\title{
Listeria monocytogenes Isolated from Illegally Imported Food Products into the European Union Harbor Different Virulence Factor Variants
}

\author{
Kathrin Rychli, Beatrix Stessl ${ }^{(D)}$, Kati Szakmary-Brändle, Anja Strauß, Martin Wagner \\ and Dagmar Schoder*
}

Institute of Milk Hygiene, University of Veterinary Medicine Vienna, Veterinärplatz 1, 1210 Vienna, Austria; kathrin.rychli@vetmeduni.ac.at (K.R.); beatrix.stessl@vetmeduni.ac.at (B.S.);

kati.szakmary-braendle@vetmeduni.ac.at (K.S.-B.); anja.strauss@lva.at (A.S.);

martin.wagner@vetmeduni.ac.at (M.W.)

* Correspondence: dagmar.schoder@vetmeduni.ac.at

Received: 6 July 2018; Accepted: 20 August 2018; Published: 23 August 2018

\begin{abstract}
Unregulated international flow of foods poses a danger to human health, as it may be contaminated with pathogens. Recent studies have investigated neglected routes of pathogen transmission and reported the occurrence of Listeria monocytogenes in food illegally imported into the European Union (EU), either confiscated at four international airports or sold illegally on the Romanian black market. In this study we investigated the genotype diversity and the amino acid sequence variability of three main virulence factors of $57 \mathrm{~L}$. monocytogenes isolates. These isolates were derived from 1474 food samples illegally imported into the EU and originated from 17 different countries. Multilocus sequence typing revealed 16 different sequence types (STs) indicating moderate genotype diversity. The most prevalent STs were ST2, ST9, and ST121. The pulsed-field gel electrophoresis (PFGE) analysis resulted in 34 unique pulsotypes. PFGE types assigned to the most prevalent STs (ST2, ST9, and ST121) were highly related in their genetic fingerprint. Internalin A (InlA) was present in 20 variants, including six truncated InlA variants, all harbored by isolates of ST9 and ST121. We detected eight ST-specific listeriolysin O (LLO) variants, and among them, one truncated form. The actin-assembly-inducing protein ActA was present in 15 different ST-specific variants, including four ActA variants with an internal truncation. In conclusion, this study shows that L. monocytogenes, isolated from illegally imported food, have moderate genotype diversity, but diverse virulence factors variants, mainly of InlA.
\end{abstract}

Keywords: Listeria monocytogenes; genotyping; virulence factors; internalin A; listeriolysin O; ActA; food; illegal; neglected routes; European Union

\section{Introduction}

Zoonooses are infectious diseases of animals that can be transmitted to humans via animal contact or by consuming contaminated water or food of animal origin. While microorganisms do not respect national borders, susceptibility to zoonotic infections is dependent upon local factors, such as hygiene practices, population or herd immunity, and the presence or absence of transmission vectors. Consequently, unregulated international flow of foods via breaches to land, sea and air route restrictions has the potential to endanger human and animal health [1].

Indeed, there have already been several disease outbreaks in humans within the European Union (EU) due to illegally imported foods of animal origin [2-4].

International airports serve as important bottlenecks for the illegal importation of products of animal origin. The urge to smuggle foreign foods may reflect the appeal of European migrants and 
travelers for exotic items for either nostalgic or religious reasons [5], or merely the desires of tourists for novel souvenirs. However, lack of food refrigeration during transit most likely facilitates pathogen enrichment beyond levels that would otherwise be anticipated.

In order to meet the challenges of protecting human and animal health, and at the same time, to ensure the continued free movement of goods and people, the EU has introduced and financed the research project PROMISE (protection of consumers by microbial risk mitigation through combating segregation of expertise). A main objective of this project was to assess the microbial risk associated with the uncontrolled import of foodstuffs, especially products of animal origin, to the customs union. Significantly, once illegal imports enter the EU they may circulate unimpeded over 28 member states and the three European Free Trade Association (EFTA) countries of Liechtenstein, Norway, and Switzerland.

One such exemplary foodborne pathogen that has raised significant attention is Listeria monocytogenes. L. monocytogenes is a facultative, intracellular pathogen responsible for listeriosis, a disease associated with severe localized and generalized infections in most domestic animals and humans $[6,7]$. Susceptible consumers of contaminated foods are typically infants, pregnant women, and the elderly, debilitated, and immunocompromised [8]. Once infection is established, the invasive form of listeriosis in humans is associated with a fatality rate of between 15-30\% [9]. The three main clinical manifestations of human listeriosis are maternofetal listeriosis, blood stream infection, and meningoencephalitis [8]. However, unlike most other bacteria, L. monocytogenes is able to survive and grow at low temperatures, high salt concentrations, and low $\mathrm{pH}$ values; conditions widely adopted to safeguard food-keeping qualities [10,11].

Previously published studies reported the occurrence of this major pathogen in food confiscated at EU airports from air passenger luggage originating from non-EU countries. Despite a range of existing regulations, recent spot-checks of the luggage of 61,355 passengers from 240 flights from non-EU countries at Vienna International Airport, involving 600 food samples, revealed the presence of foodborne bacteria in $5 \%$ of all samples [12]. The highest prevalence of foodborne pathogens in this study was attributed to L. monocytogenes at $2.5 \%$. Similarly, related studies identified L. monocytogenes in $10 \%$ of foods seized at the International Airport of Bilbao, Spain [13] and in 1.4\% of illegally imported food at two German airports (Frankfurt International and Berlin-Schönefeld Airport) [5]. Additionally L. monocytogenes was detected in $7.5 \%$ of foods illegally sold at the Romania-Republic of Moldova border [14].

The aim of this study was to investigate the genotype diversity and virulence gene variations of 57 L. monocytogenes isolates from 1474 food samples illegally imported into or sold within the EU. Therefore we performed multilocus sequence typing (MLST), pulsed-field gel electrophoresis (PFGE), and analyzed the full-length amino acid sequences of three essential virulence genes: InlA, required for the invasion of L. monocytogenes into the host cells [15]; listeriolysin O (LLO), a pore-forming toxin of the cholesterol-dependent cytolysin (CDC) family, essential for phagosomal escape, intracellular growth, and cell-to-cell spread [16]; and the actin assembly-inducing protein ActA. ActA is responsible for bacterial movement and cell-to-cell spread [17], and has recently been shown to be also involved in biofilm formation and aggregation as well as long-term colonization of the gastrointestinal tract [18].

\section{Materials and Methods}

\subsection{Listeria monocytogenes Isolates}

All L. monocytogenes isolates used in this study were isolated within the Seventh Framework Programme (FP7) EU project "PROMISE-protection of consumers by microbial risk mitigation through segregation of expertise" from food products illegally imported into the EU. Briefly, food samples were confiscated by EU border inspection forces from passengers' luggage travelling through four international airports: Vienna International Airport (Austria) [12], Bilbao Airport (Spain) [13], Frankfurt International Airport, and Berlin-Schönefeld Airport (both Germany) [5]. Additionally, food products 
were sampled from a black market in Galati, Romania [14,19]. These food samples were analyzed for the presence of L. monocytogenes according the ISO 11290-1 (1996).

\subsection{Multilocus Sequence Typing and Pulsed-Field Gel Electrophoresis Typing}

Multilocus sequence typing (MLST), which is based on seven housekeeping genes (abcZ (ABC transporter), bglA (beta glucosidase), cat (catalase), dapE (succinyl-diaminopimelate desuccinylase), dat (D-amino acid aminotransferase), ldh (L-lactate dehydrogenase), lhkA (histidine kinase)) was performed according to Ragon et al. [20]. PCR products were sequenced (LGC Genomics, Berlin, Germany), and an allele number was assigned to each housekeeping gene. Sequence type (ST) numbers were attributed to each distinctive allele combination using the Institute Pasteur L. monocytogenes MLST database. A detailed protocol of the MLST procedure, including primers, PCR conditions, and allelic type, are available at the Institute Pasteur website (http:/ /bigsdb.pasteur. $\mathrm{fr} /$ listeria/listeria.html). Classification of the STs into clonal complexes (CCs) was performed according to Canticelli et al. [21]. MLST data of L. monocytogenes isolates from food confiscated at the airport Vienna, Austria [12]; Bilbao, Spain [13]; and the black market in Galati, Romania [19]; were included. The MLST genes were concatenated for each strain, resulting in 3288 nucleic acids and aligned using MUSCLE implemented in MEGA7 using the Tamura-Nei evolutionary model and the maximum likelihood treeing method [22]. Gapless alignments were checked manually.

Pulsed-field gel electrophoresis (PFGE) typing applying the restriction enzymes AscI and ApaI was performed according to the standardized PulseNet International protocol [23].

Restricted DNA was electrophoresed on 1\% (w/v) SeaKem gold agarose (Lonza Group AG, Basel, Switzerland) in $0.5 \times$ TBE at $6 \mathrm{~V} / \mathrm{cm}$ on a Chef DR III system (Bio-Rad Laboratories, Inc., Hercules, CA, USA). A linear ramping factor with pulse times from 4.0 to $40.0 \mathrm{~s}$ at $14{ }^{\circ} \mathrm{C}$, and an included angle of $120^{\circ}$ was applied for $22.5 \mathrm{~h}$. Gels were stained with ethidium bromide (Sigma Aldrich, St. Louis, MO, USA), digitally photographed with Gel Doc 2000 (Bio-Rad Laboratories, Inc.), and normalized as TIFF images (BioNumerics 6.6 software Applied Math NV, Sint-Martens-Latem, Belgium) using the PFGE global standard Salmonella ser. Braenderup H9812. Pattern clustering was performed using the unweighted pair group method, including arithmetic averages (UPGMA) and the Dice correlation coefficient with a position tolerance of $1.5 \%$. PFGE types with no band difference were considered as 100\% similar, respectively genetically indistinguishable, according to Tenover et al. [24]. The Simpson's index of diversity on the combined PFGE cluster analysis (AscI and ApaI) was calculated applying the online tool of comparing partitions (http:/ / www.comparingpartitions.info/).

\subsection{Sequencing and Analysis of Virulence Genes}

PCR amplification was performed for the following genes: act A (2121 bp), hly (1587 bp) and inlA (2400 bp) using specific primers (Table S1). PCR conditions were as follows: $0.2 \mathrm{pmol} / \mu \mathrm{L}$ of each primer, $2 \mathrm{mM} \mathrm{MgCl}_{2}, 1 \mathrm{mM}$ dNTP-Mix, 0.625U Platinum Taq DNA polymerase (Life Technologies, Carlsbad, CA, USA). PCR cycling conditions for inlA and $h l y$ were $95^{\circ} \mathrm{C}$ for $2 \mathrm{~min}, 35$ cycles at $94^{\circ} \mathrm{C}$ for $1 \mathrm{~min}, 58{ }^{\circ} \mathrm{C}$ for $40 \mathrm{~s}$ and $72{ }^{\circ} \mathrm{C}$ for $2.5 \mathrm{~min}$, and a final elongation at $72{ }^{\circ} \mathrm{C}$ for $5 \mathrm{~min}$; and for act $A$ were $95{ }^{\circ} \mathrm{C}$ for $2 \mathrm{~min}$, followed by 35 cycles at $94{ }^{\circ} \mathrm{C}$ for $1 \mathrm{~min}, 62{ }^{\circ} \mathrm{C}$ for $40 \mathrm{~s}$ and $72{ }^{\circ} \mathrm{C}$ for $2.5 \mathrm{~min}$, and a final extension at $72{ }^{\circ} \mathrm{C}$ for $5 \mathrm{~min}$. Distilled water was included as a negative control in each PCR. PCR products for $h l y$ and inlA were sequenced using the universal sequencing MLST primers. For sequencing the act $A$ PCR products we used the forward and reverse primers of the corresponding PCR reaction (Table S2; LGC Genomics).

Sequences were joined to full length sequences using MAFFT [25] and translated into amino acid sequences (http://web.expasy.org/translate/). The InlA and LLO amino acid sequences of the L. monocytogenes strains Ro01-15, included in this study, have been analyzed in a recent project [19]. Amino acid sequences were aligned with MAFFT; alignments were visualized using BOXSHADE (http:/ / www.ch.embnet.org/software/BOX_form.html). The phylogenetic analysis and the estimation of the overall mean distance were performed using MUSCLE implemented in 
MEGA7 [22]. The analysis involved 57 amino acid sequences. After alignment we used the maximum likelihood method based on the Jones-Taylor-Thornton (JTT) matrix-based model for the phylogenetic analysis, including bootstrap analysis, to estimate the reliability (number of bootstrap repetitions 100) [26] and the Poisson model to estimate the overall mean distance. All positions with less than $75 \%$ site coverage-meaning fewer than $25 \%$ alignment gaps, missing data, and ambiguous bases-were allowed at any position. This resulted in 800 positions for InlA in the final set, 529 for LLO, and 633 for ActA.

\subsection{Nucleotide Sequence Accession Number}

The nucleotide sequences have been deposited in GenBank under the following accession numbers: inlA of isolate 1_5 (ST2): MG922914, 6_3 (ST37): MG922915, Ro05 (ST155): MG922916 6_14 (ST155) MG922917 and 6_20 (ST199) MG922918; hly of isolate Ro05 (ST155) MG922919 and 1_5 (ST2) MG922920; and actA of isolate Ro05 (ST155): MG922921 and 6_20 (ST199) MG922922. For all other sequences, homologous sequences sharing $100 \%$ nucleotide identity were found in the NCBI database using BLAST.

\section{Results and Discussion}

\subsection{Strain Characteristics and Genotype Diversity}

In total, we have isolated 57 L. monocytogenes isolates from 1474 food products imported from 17 different non-EU countries (Table 1, Table S1). That corresponds to a prevalence of $3.87 \%$. Of these, 28 isolates originated from Asia, and among them, 50\% were from Turkey $(n=14)$ and $21 \%$ from Russia $(n=6)$, which reflects the high numbers of Austrian and German immigrants originating from Turkey and Russia. Additionally, 18 isolates originated from non-EU countries in Europe, of these, $83 \%$ were from the Republic of Moldova $(n=15), 11 \%$ from Ukraine $(n=2)$, and one strain was from Albania (Table 1). The origin of ten L. monocytogenes isolates was South America. Only one L. monocytogenes positive food sample derived from Africa (Table 1).

Table 1. Origin of Listeria monocytogenes isolates assigned to sequence types (STs).

\begin{tabular}{ccc}
\hline Continent & Country & STs \\
\hline Africa $(n=1)$ & Morocco $(n=1)$ & $199(n=1)$ \\
\hline & Armenia $(n=1)$ & $18(n=1)$ \\
Asia $(n=28)$ & China $(n=5)$ & $8,9,121(n=1) ; 87(n=2)$ \\
& Georgia $(n=1)$ & $2(n=1)$ \\
& Nepal $(n=1)$ & $308(n=1)$ \\
& Russia $(n=6)$ & $5,9,11,37(n=1) ; 121(n=2)$ \\
Europe $(n=18)$ & Turkey $(n=14)$ & $3,5,37(n=1) ; 1(n=2) ; 121(n=4) ; 9(n=5)$ \\
& Albania $(n=1)$ & $2(n=1)$ \\
& Republic of Moldova $(n=15)$ & $2,9(n=1) ; 8,21(n=2) ; 155(n=4) ; 20(n=5)$ \\
& Ukraine $(n=2)$ & $2,37(n=1)$ \\
\hline & Argentina $(n=1)$ & $2(n=1)$ \\
South America $(n=10)$ & Bolivia $(n=1)$ & $9(n=1)$ \\
& Brazil $(n=1)$ & $155(n=1)$ \\
& Colombia $(n=2)$ & $87,378(n=1)$ \\
& Ecuador $(n=3)$ & $2(n=3)$ \\
& Peru $(n=1)$ & $2(n=1)$ \\
& Venezuela $(n=1)$ & $87(n=1)$ \\
\hline
\end{tabular}

Sixty-three percent of L. monocytogenes isolates derived from meat and meat products (36/57), whereas 11 isolates originated from fish (19\%), and nine from dairy products (16\%, Table 2, Table S1). 
Table 2. L. monocytogenes ST distribution among different food categories.

\begin{tabular}{cc}
\hline Food Source & STs \\
\hline Dairy $(n=9)$ & $1,3,5,9,121(n=1)$ \\
& $2(n=4)$ \\
\hline Fish $(n=11)$ & $2,8,121(n=1)$ \\
& $20,155(n=4)$ \\
\hline & $1,5,11,18,20,155,199,308,378(n=1)$ \\
& $37(n=2)$ \\
Meat $(n=36)$ & $2,87(n=4)$ \\
& $121(n=6)$ \\
& $9(n=8)$ \\
\hline Other $(n=1)$ & $121(n=1)$ \\
\hline
\end{tabular}

In comparison to illegally imported food products, $343 \mathrm{~L}$. monocytogenes notifications in food and feed were reported in the same period (2012 to 2015) within the Rapid Alert System for Food and Feed, which is a system for reporting food safety issues within the EU (RASSF portal; https: / / ec.europa.eu/food/safety/rasff_en). This represents $11.86 \%$ of all notifications on pathogenic microorganisms within the EU. The highest L. monocytogenes notification rates were identified in fish $(n=127)$, milk and milk products $(n=99)$, and meat products $(n=74)$.

Of the 57 isolates, 20 belong to lineage I and 37 strains to lineage II. MLST typing revealed 16 different STs belonging to 15 CCs (Figure 1, Simpson's diversity index 0.909). The most prevalent STs were ST2, ST9, and ST121 comprising each of nine isolates, followed by ST20 $(n=5)$ and ST155 $(n=5)$. Eight STs comprised only one or two isolates. The predominant genotypes of L. monocytogenes isolated from meat and meat products were ST121 and ST9; whereas ST20, ST155, and ST2 were most prevalent in fish and dairy products, respectively (Table 2).

This is in accordance with a recent study from the European Food Safety Authority analyzing the core genome MLST of 1143 L. monocytogenes isolates. The 10 predominant CCs (CC121, CC9, CC8, CC1, CC2, CC155, CC87, CC3, CC37, CC5, CC20, and CC18; provided in descending order) were also identified in our study [27].

Due to the diverse origins of the L. monocytogenes strains (17 different counties), we initially, would have expected higher genotype diversity. A recent study, including 300 L. monocytogenes strains from different sources (human, food, environment, and animals) from 42 countries in five continents showed a high diversity [28]. The 300 isolates represented 111 STs grouped into 17 CCs. The most prevalent CCs were CC2, CC1, and CC3, all belonging to lineage I [28]. Strains of ST2 (CC2) were also highly prevalent in our study; whereas, we detected only three strains of CC1 and one isolate belonging to CC3. Strains of CC1 are known to be overrepresented in clinical isolates [29]. However, our study included only L. monocytogenes isolated from food sources. The other two of the three highly abundant STs in our study, mainly ST9 and ST121, are known to be the most abundant STs, at least in Europe, and are overrepresented in food and food-associated environments [27,29]. Moreover, a recent study analyzing the population diversity of L. monocytogenes strains of diverse geographical locations showed that ST9 and ST121 have the highest geographical transition rates [30]. 
MLST

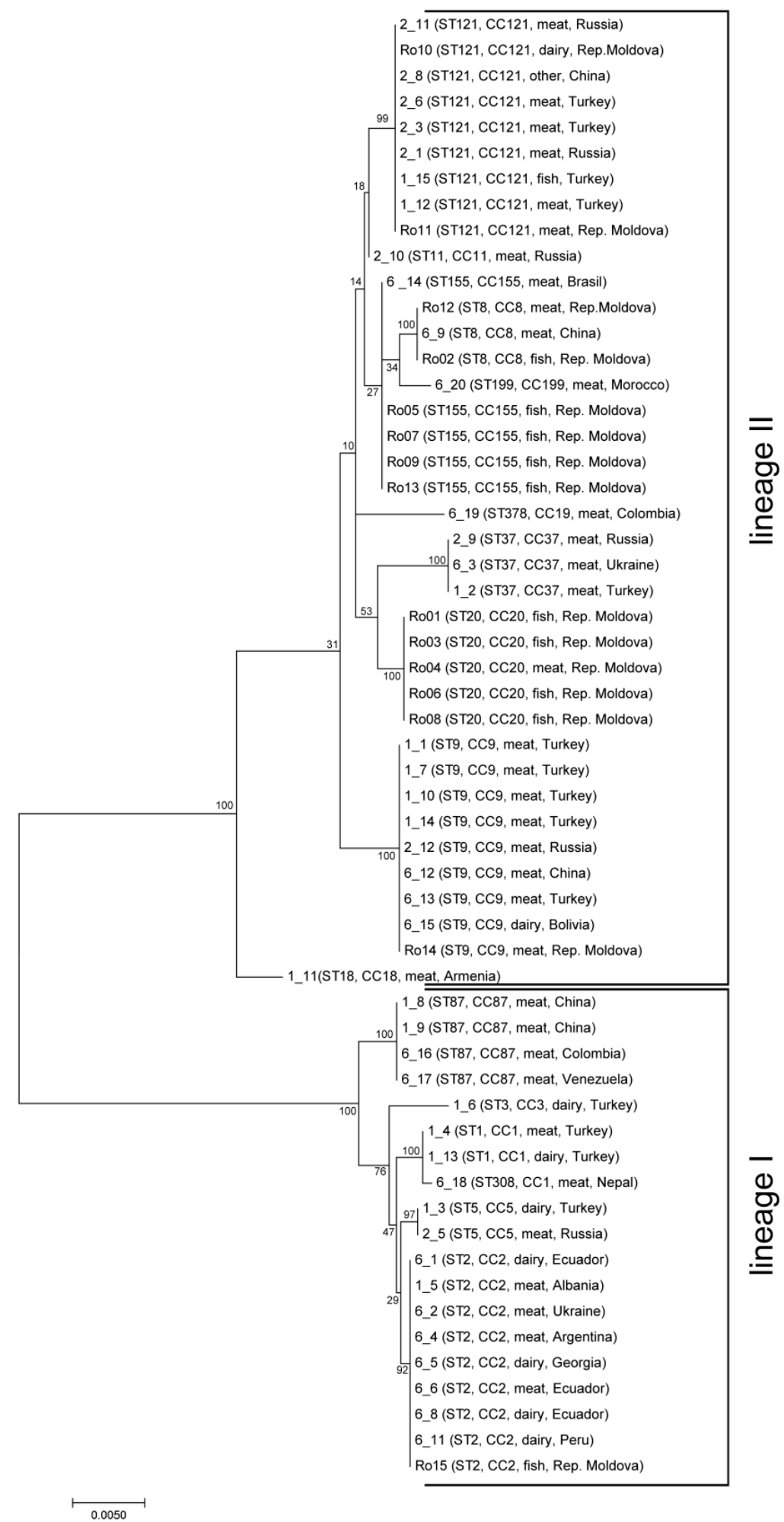

Figure 1. Maximum likelihood phylogenetic tree of Listeria monocytogenes strains based on multilocus sequence typing (MLST) loci. The maximum likelihood phylogenetic tree is based on concatenated full-length MLST gene sequences and was calculated with MEGA7 using the Tamura-Nei model. Bootstrap values $(100 \times$ resampling) are indicated at the respective nodes. The analysis involved 57 nucleotide sequences. All positions containing gaps were eliminated. There was a total of 3288 positions in the final dataset. The bar represents the number of substitutions per site. L. monocytogenes sequence types (STs), clonal complexes (CCs), source, and the origin country, are indicated. 
Sequence type 155 strains, represented by five isolates in our study, have shown only a moderate prevalence among European and international strains [27-29]. Recently, ST155 isolates were involved in human listeriosis cases reported from Denmark [31]. ST20 strains, also represented by five isolates, appear to be rare, and rather environmentally associated, especially to silage and animals [32]. Interestingly, ST199, originating in this study from a meat product in Morocco, was also present in legally sold Moroccan food products (2009-2015) [33].

The PFGE typing of 57 L. monocytogenes isolates, with the restriction enzyme AscI and ApaI, resulted in 25 and 30 different pulsotypes, respectively. PFGE analyses combining the results obtained with both restriction enzymes identified 34 unique pulsotypes, resulting in a Simpson's diversity index of 0.971 (Figure 2).

L. monocytogenes isolates assigned to PFGE type IIF-9-1, IIF-9-2, IIF-121-1, IIF-121-5, and II-2-2 were $100 \%$ similar within their fingerprint profile, and seem to be widely distributed (Figure 2). The latter PFGE profiles were identified as ST9 (IIF-9-1, IIF-9-2), ST121 (IIF-121-1, IIF-121-5; genetic lineage II), and ST2 (II-2-2; genetic lineage I) which are common STs persistent in food processing environments $[28,29,34]$. Furthermore, indistinguishable isolates were observed in PFGE-profile IIF-8-1, IIF-37-1, and IIF-87-2 (each $n=2$ ) corresponding to ST8, ST37, and ST87 (Figure 2). ST8 isolates are also related to persistence, especially in the fish and meat processing chain [34,35]. ST37 representatives are rather rare and were most recently isolated from nature and cheese processing environment $[32,36]$. ST87 are both human outbreak and food associated and frequently reported from China [37].

Furthermore, indistinguishable PFGE types were also found among isolates from illegally sold fish and meat products at a black market in Romania. In detail, PFGE type IIF-20-2 and IIF-155-2 were identified among 4 and 3 different food products, respectively. Cross-contaminations with the same Listeria isolate are highly probable.

In summary, the discriminatory power of PFGE method was superior in comparison with MLST (Simpson's diversity index of 0.971 versus 0.909 ), resulting in 34 combined AscI/ApaI profiles. Apparently, PFGE typing is a good complementary method to the MLST, and even to genome multilocus sequence typing (cgMLST) where subtypes related to rearrangements in the accessory genome (uptake or loss of prophages, plasmids) can be identified [38]. 


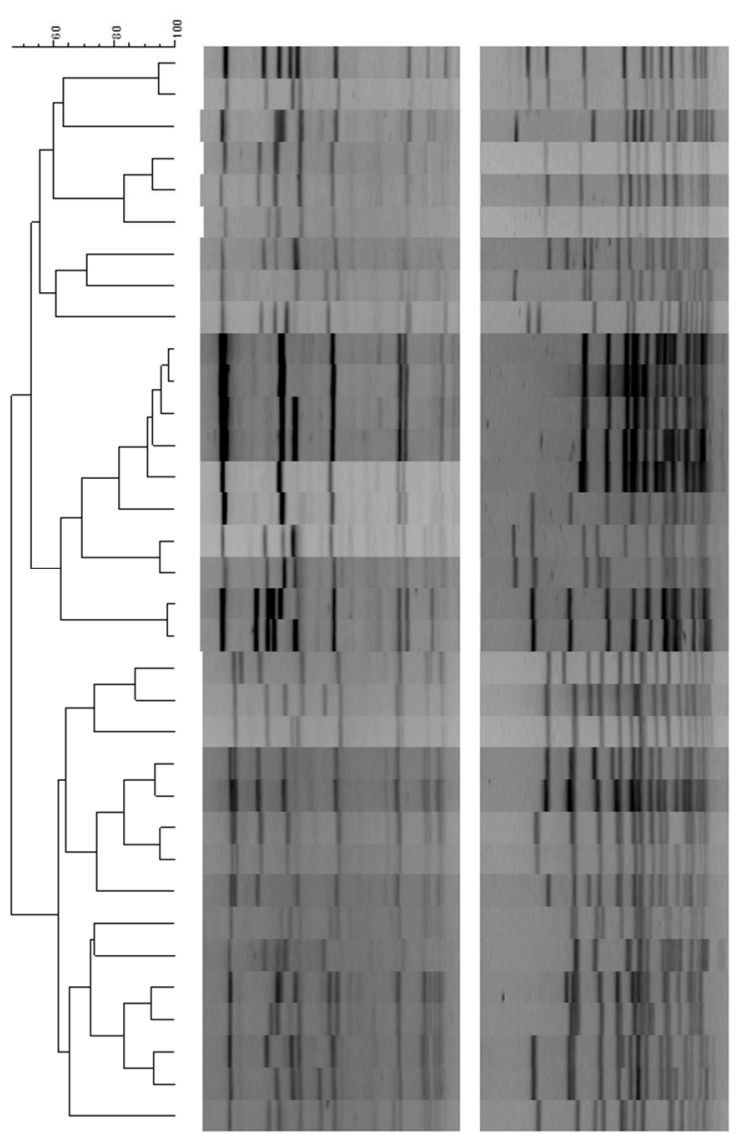

\begin{tabular}{|c|c|c|c|c|c|c|}
\hline n & Isolate ID & PFGE-type & $\mathbf{C C}$ & ST & Source & Country \\
\hline 6 & 1_7,1_10,6_12,6_13,6_15,Ro14 & IIF-9-1 & 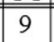 & 9 & meat, dairy & Turkey, Rep. Moldova, China, Bolivia \\
\hline 3 & 1_1, 1_14,2_12 & IIF-9-2 & 9 & 9 & meat & Turkey, Russia \\
\hline 1 & $1 \_11$ & IIF-18-1 & 18 & 18 & meat & Armenia \\
\hline 2 & $6-\overline{9}, \mathrm{Ro} 2$ & IIF-8-1 & 8 & 8 & meat, fish & China, Rep. Moldova \\
\hline 1 & Ro03 & IIF-20-1 & 20 & 20 & fish & Rep. Moldova \\
\hline 1 & Ro12 & IIF-8-2 & 8 & 8 & meat & Rep. Moldova \\
\hline 4 & Ro04,Ro08, Ro06, Ro01 & IIF-20-2 & 20 & 20 & fish, meat & Rep. Moldova \\
\hline 1 & 2_10 & IIF-11-1 & 11 & 11 & meat & Russia \\
\hline 1 & $6 \_20$ & IIF-199-1 & 199 & 199 & meat & Marocco \\
\hline 3 & $2 \_3,2 \_6,2 \_8$ & IIF-121-1 & 121 & 121 & other, meat & China, Turkey \\
\hline 1 & Ro11 & IIF-121-2 & 121 & 121 & meat & Rep. Moldova \\
\hline 1 & 2_11 & IIF-121-3 & 121 & 121 & meat & Russia \\
\hline 1 & 2_1 & IIF-121-4 & 121 & 121 & meat & Russia \\
\hline 3 & 1_12,1_15, Ro10 & IIF-121-5 & 121 & $121 \mathrm{f} i$ & ish, meat, dairy & Turkey, Rep. Moldova \\
\hline 1 & $6 \_14$ & IIF-155-1 & 155 & 155 & meat & Brasil \\
\hline 2 & 12,29 & IIF-37-1 & 37 & 37 & meat & Turkey, Russia \\
\hline 1 & $63^{-}$ & IIF-37-2 & 37 & 37 & meat & Ukraine \\
\hline 3 & Ro05, Ro07, Ro13 & IIF-155-2 & 155 & 155 & fish & Rep. Moldova \\
\hline 1 & Ro09 & IIF-155-3 & 155 & 155 & fish & Rep. Moldova \\
\hline 1 & $6 \_18$ & IIF-308-1 & 1 & 308 & meat & Nepal \\
\hline 1 & 1 & IIF-1-1 & 1 & 1 & dairy & Turkey \\
\hline 1 & 1_4 & IIF-1-2 & 1 & 1 & meat & Turkey \\
\hline 1 & 68 & IIF-2-1 & 2 & 2 & dairy & Ecuador \\
\hline 5 & $6 \_2,6 \_4,6 \_5,6 \_6,6 \_11$ & IIF-2-2 & 2 & 2 & dairy, meat & Ukraine, Georgia, Argentina, Peru \\
\hline 1 & -15 & IIF-2-3 & 2 & 2 & meat & Albania \\
\hline 1 & $6 \_1$ & IIF-2-4 & 2 & 2 & dairy & Ecuador \\
\hline 1 & Ro15 & IIF-2-5 & 2 & 2 & fish & Rep. Moldova \\
\hline 1 & $6 \_17$ & IIF-87-1 & 87 & 87 & meat & Venezuela \\
\hline 1 & 6_19 & IIF-378-1 & 19 & 378 & meat & Colombia \\
\hline 2 & 18,19 & IIF-87-2 & 87 & 87 & meat & China \\
\hline 1 & $6 \_16$ & IIF-87-3 & 87 & 87 & meat & Colombia \\
\hline 1 & 13 & IIF-5-1 & 5 & 5 & dairy & Turkey \\
\hline 1 & 25 & IIF-5-2 & 5 & 5 & meat & Russia \\
\hline 1 & 16 & IIF-3-1 & 3 & 3 & dairy & Turkey \\
\hline
\end{tabular}

Figure 2. Combined pulsed-field gel electrophoresis (PFGE) cluster analysis of 57 L. monocytogenes isolates. Combined PFGE cluster analysis of L. monocytogenes isolates from this study (restriction enzymes AscI \& ApaI). The TIFF images were compared using BioNumerics 6.6 software (Applied Math NV, Sint-Martens-Latem, Belgium), and normalized using the PFGE global standard Salmonella ser. Braenderup H9812. Pattern clustering was performed using the unweighted pair group method using arithmetic averages (UPGMA) and the Dice correlation coefficient was applied with a position tolerance of $1.5 \%$. 


\subsection{InlA Variants}

We detected a high diversity in the InlA amino acid sequence of the 57 international L. monocytogenes isolates with an overall mean distance estimation of 0.013 . In total, we detected 20 different variants (Figure 3), and among them, six variants have a truncated InlA due to the presence of a premature stop codon (PMSC).

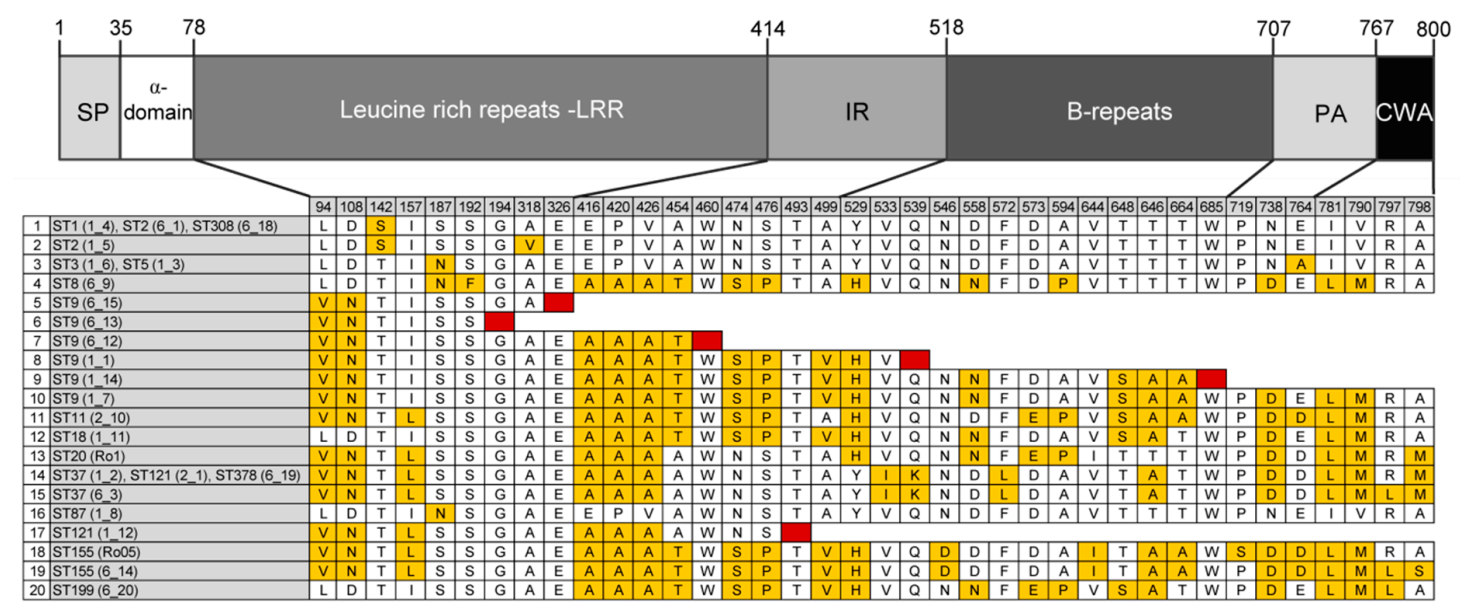

Figure 3. Internalin A variants. Analysis of InlA amino acid sequence of 57 L. monocytogenes isolates revealed 20 different variants. InlA functional domains are represented as distinct blocks: signal peptide (SP), leucine rich repeats (LRR), intragenic repeat (IR), B-repeats, pre-anchor domain (PA), and cell wall anchor (CWA). Different variants are presented by one representative strain. Red indicates premature stop codon (PMSC).

The truncated form of InlA is secreted, rather than anchored in the cell wall, leading to attenuated virulence and reduced pathogenicity [39-41]. To date, 30 different frameshifts and mutations leading to PMSC are known [30]. In total, 14 isolates (24.6\%), all belonging to ST9 or ST121, harbor a truncated inlA gene (Figure 3). All ST121 isolates, except isolate 2_1, have a PMSC at position 492 (mutation type 6 [42]). ST121 strains, whose genomes are highly conserved, are known to harbor this specific PMSC type in the inlA sequence [30,43,44]. Interestingly, isolate 2-1 has a full-length InlA, identical to isolate 6_19 (ST378). ST121 strains carrying a full-length InlA are very rare, and have so far only been reported for a second strain, the human isolate SLCC1589 [43]. ST121 strains, although highly abundant, are known to be underrepresented among human isolates [28,29,45]. A recent study, including in total 1167 ST121 strains, among them, 82 human isolates, reported that ST121 isolates (79\%) induced mainly bacteremia, whereas $20 \%$ create an infection of the central nervous system [29]. This clearly shows that ST121 strains have the potential to cause listeriosis, despite the presence of a truncated InlA.

The ST9 isolates carry, in contrast to ST121 isolates, different InlA variants, suggesting a higher genetic diversity in this ST group. Three ST9 isolates have a full length InlA. We detected five different InlA PMSCs harbored by six ST9 isolates: at position 194 AA (mutation type 27 [30], strain 6_13), at position 326 AA (mutation type 19 [46], strain 6_15), at position 460 AA (mutation type 8 [47], strain 6_12 and Ro14), at position 539 (mutation type 14 [20], strain 1_1), and at position 685 (mutation type 11 [47], strain 1_14). In a recent study analyzing the genome of 1696 L. monocytogenes strains, including 70 ST9 strains, seven different mutations leading to a PMSC in the inlA gene have been reported [30].

Further, we detected alterations in all structural motifs of InlA, except the signal peptide and the $\alpha$-domain (Figure 3). The most conserved region of InlA among the 57 L. monocytogenes isolates was the LRR domain (2.08\% of all AA positions), which is fundamental for the binding to E-cadherin to the host cell [48]. By contrast, the cell wall anchoring (CWA) domain, at the carboxyl-terminal including the LPXTG motif, which anchors the protein to peptidoglycan of the bacterial cell wall [49], 
and the inter-repeat (IR) domain, showed a high variation in $12.12 \%$ and $6.73 \%$ of amino acid positions, respectively. In parallel, Ragon et al. have reported a highly constrained LRR region, and moderately constrained IR and B-repeat regions [20].

The phylogenetic tree, including the InlA amino acid sequences of all 57 L. monocytogenes isolates (site coverage $\geq 75 \%$ ), reveals that not all isolates of the same ST harbor the same InlA variant, and that isolates of different STs can carry the same InlA variant (Figure 4).

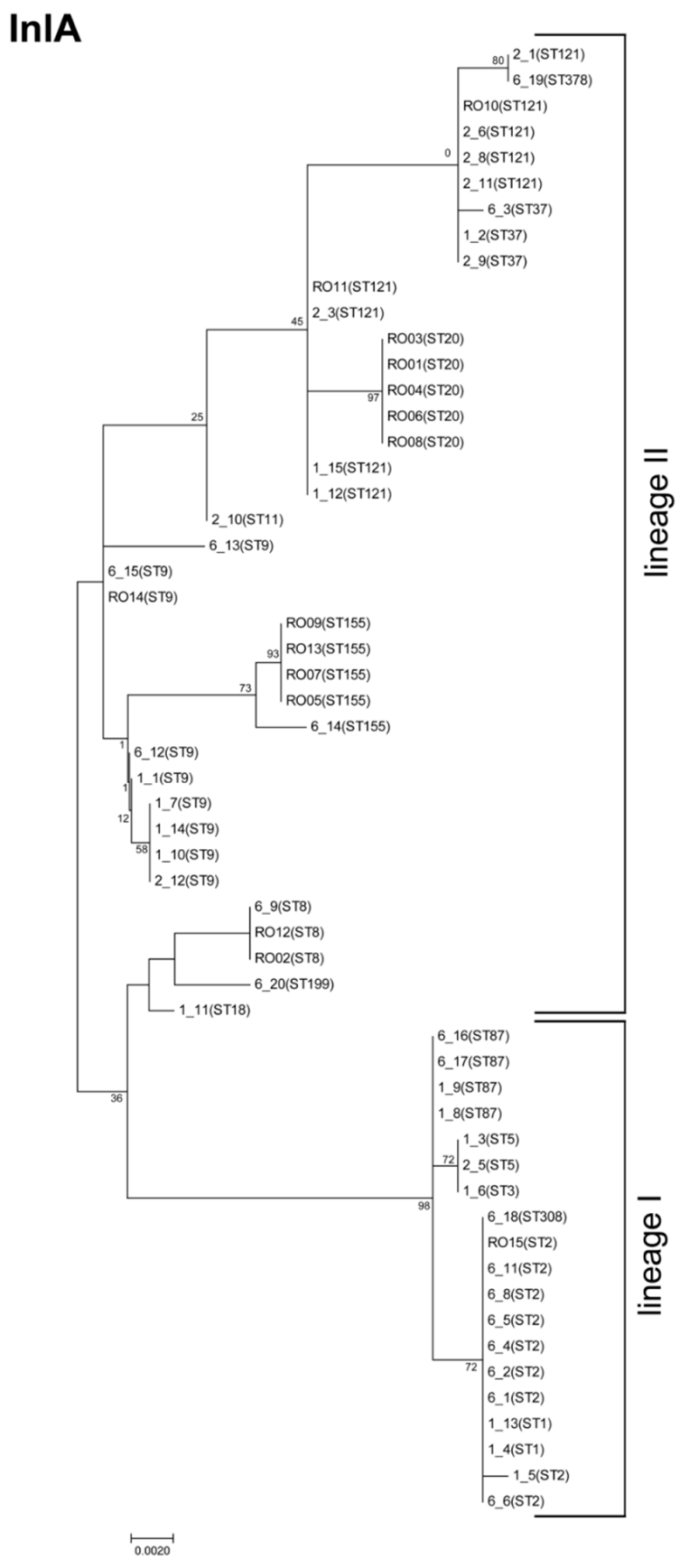

Figure 4. Phylogenetic analysis of internalin A. The molecular phylogenetic analysis by the maximum likelihood method is based on InlA amino acid sequences, and was calculated with MEGA7 using the Jones-Taylor-Thornton (JTT) matrix-based model [22,26]. The tree is drawn to scale, with branch lengths measured by the number of substitutions per site. Bootstrap values $(100 \times$ resampling) are indicated at the respective nodes. The analysis involved 57 amino acid sequences. All positions with less than $75 \%$ site coverage were eliminated, resulting in 800 positions in the final dataset. 


\subsection{Listeriolysin $O$ Variants}

We also sequenced the hly gene and analyzed the corresponding amino acid sequence of LLO, a pore-forming toxin of the CDC family. We detected a lower diversity in the LLO amino acid sequence compared to InlA, with an overall mean distance estimation of 0.003 (shown also in the phylogenetic tree, Figure 5).

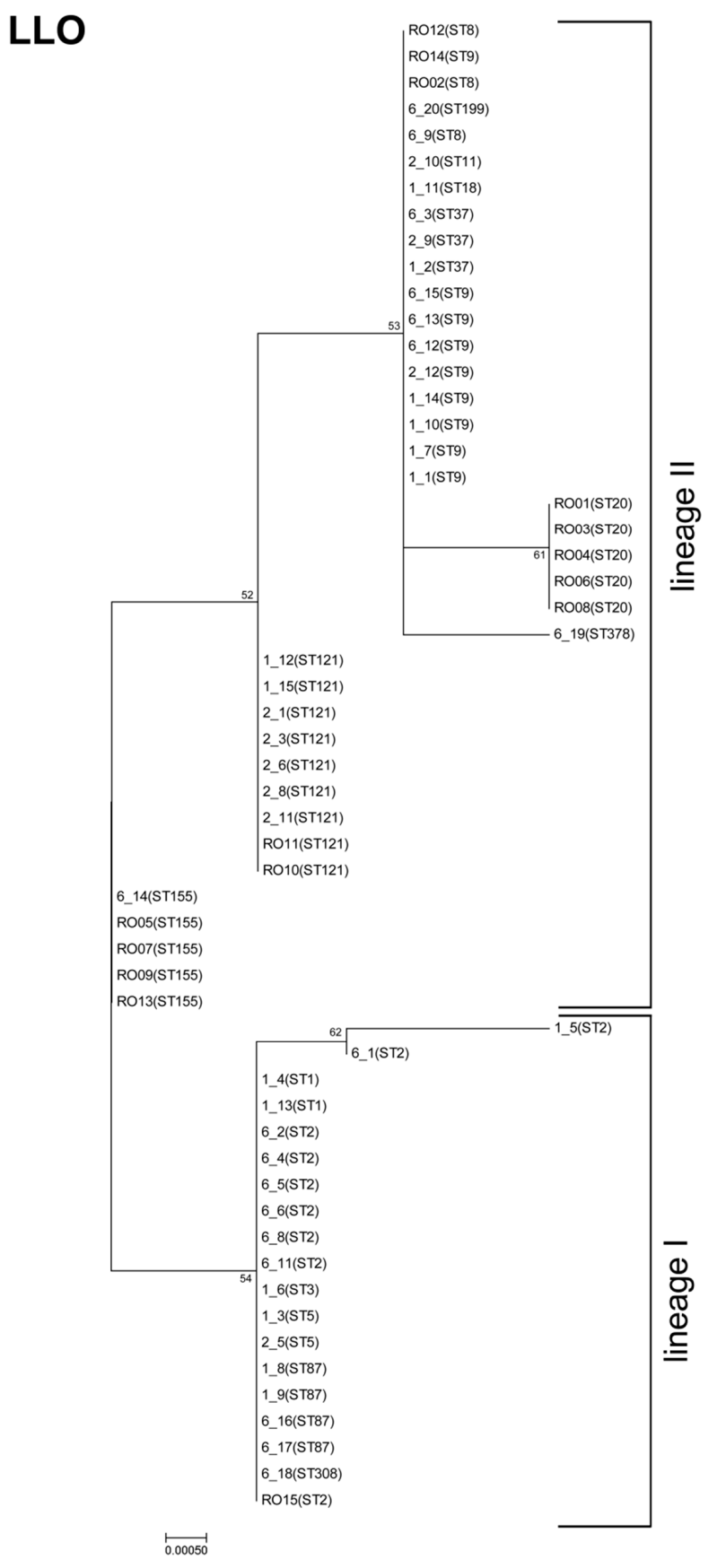

Figure 5. Phylogenetic analysis of listeriolysin O (LLO). The molecular phylogenetic analysis by the maximum likelihood method is based on InlA amino acid sequences, and was calculated with MEGA7 using the JTT matrix-based model [22,26]. The tree is drawn to scale, with branch lengths measured in the number of substitutions per site. Bootstrap values $(100 \times$ resampling $)$ are indicated at the respective nodes. The analysis involved 57 amino acid sequences. All positions with less than $75 \%$ site coverage were eliminated, resulting in 529 positions in the final dataset. 
Listeriolysin O was present in eight different variants. Isolates belonging to the same ST harbored the same LLO sequence (except the two ST2 strains). The phylogenetic tree clearly shows a distinction among the LLOs of isolates from lineage I and II (Figure 5). This is in line with previous studies showing that distinct genetic lineages of L. monocytogenes have characteristic ribotypes with the hly allelic types [50].

One isolate (1_5, ST2) carries a PMSC in the hly gene, resulting in a truncated LLO (293 AA), which lacks the $\mathrm{pH}$ regulation domain and the cholesterol-binding motif. PMSCs in the hly gene appear to be very rare. So far, only one study that analyzed the genome of 104 strains reported the presence of truncated LLO in one strain, which was also from CC2 (ST553) [29]. However, it remains unclear whether PMSC in the hly gene is restricted to strains of CC2 (lineage I).

We observed an alternation in the $\mathrm{N}$-terminus at position $35(\mathrm{~L} / \mathrm{S})$, the region containing the 26 aa PEST motif (including the amino acids $\mathrm{P}, \mathrm{E}, \mathrm{S}$, and T), which is involved in phagosomal escape of bacteria in infected cells [51-53]. Further, we observed alterations in the CDC four-domain structure at positions $119(\mathrm{~N} / \mathrm{D})$ and $185(\mathrm{~V} / \mathrm{I})$; near the $\mathrm{pH}$ regulation domain at positions $375(\mathrm{~V} / \mathrm{I}), 433(\mathrm{~V} / \mathrm{I})$, and $438(\mathrm{~V} / \mathrm{I})$; and at the C-terminus at positions $523(\mathrm{~S} / \mathrm{K}), 524(\mathrm{D} / \mathrm{V})$, and $525(\mathrm{D} / \mathrm{V})$. Various studies have shown that mutations in the $\mathrm{pH}$ regulation domain and at the $\mathrm{C}$ terminus, which includes the cholesterol binding motif, attenuate the virulence of L. monocytogenes [54-57].

\subsection{ActA Variants}

Among all three of the analyzed virulence factors, ActA showed the second highest variation with an overall mean distance estimation of 0.272 (compared to 0.013 for InlA and 0.003 for LLO). The high overall mean distance estimation factor reflects the presence of internal truncation in ActA, which is harbored by $24.6 \%$ of isolates $(n=14)$.

We detected four ActA variants with an internal truncation: one of which was present in all ST121 isolates (lineage II). Additionally, all ST1, ST5, and ST308 isolates (all lineage I) carry an internal ActA truncation (Figure 6). All these short ActA variants, comprising of 598 amino acids, harbor only three proline rich repeats (PRR) domains compared to four PRR domains (633 amino acids). Internal truncation of ActA appears to be common, and also occurs in strains of other STs [29].

In total, we detected 15 different ST specific variants with one exception: ST37 and ST155 isolates carry the same ActA variant (Figure 6). Variations in the amino acid sequence occurred in all structural domains of ActA, except the signal peptide domain. Variations were present in $10.5 \%$ of the amino acids of the $\mathrm{N}$-terminus, which contain the actin-binding domain and other regions required for the initiation of actin polymerization [58], in $11.4 \%$ of amino acids of the central region containing either three or four PRR separated by long-repeat regions [59], and in $16.5 \%$ of the amino acids of the C-terminus, containing the transmembrane domain responsible for anchoring ActA to the bacterial surface [58]. The central domain of ActA is not required for actin-based motility, but influences the speed of movement $[60,61]$. Studies examining the effects of different ActA variants on the virulence potential of L. monocytogenes are rare and have produced inconsistent results [18,62].

The phylogenetic tree of ActA shows a clear distinction between isolates with and without an internal truncation (Figure 7). We observed an additional distinction between isolates of lineage I and II in these two clusters. 


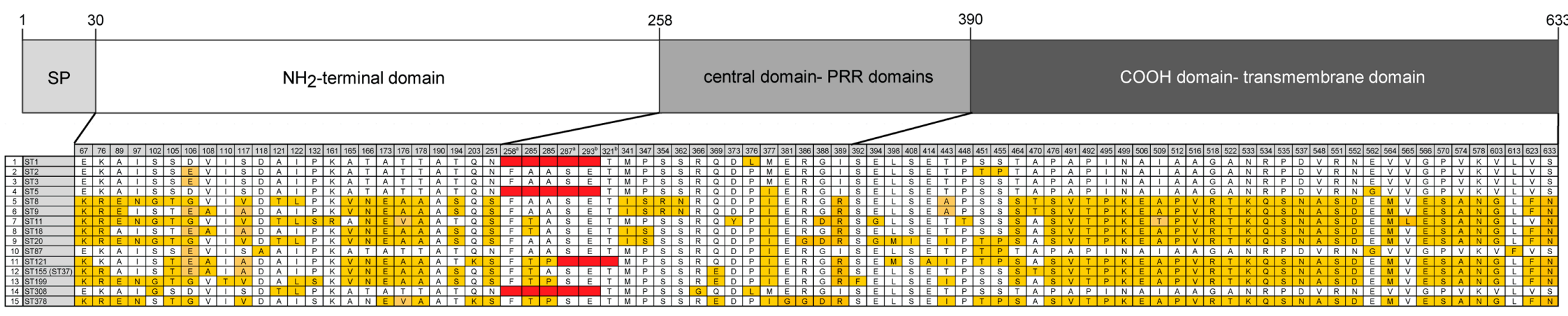

Figure 6. ActA variants. Analysis of ActA amino acid sequence of 57 L. monocytogenes isolates revealed 15 different variants. ActA functional domains are represented as distinct blocks. SP: signal peptide, PRR: proline reach repeat; Different variants are presented by isolates of the same ST with two exceptions. ST37 and ST155 isolates harbor the same ActA variant. Red indicates internal truncation. ${ }^{a}$ start and ${ }^{\mathrm{b}}$ end of the internal truncation. 
ActA

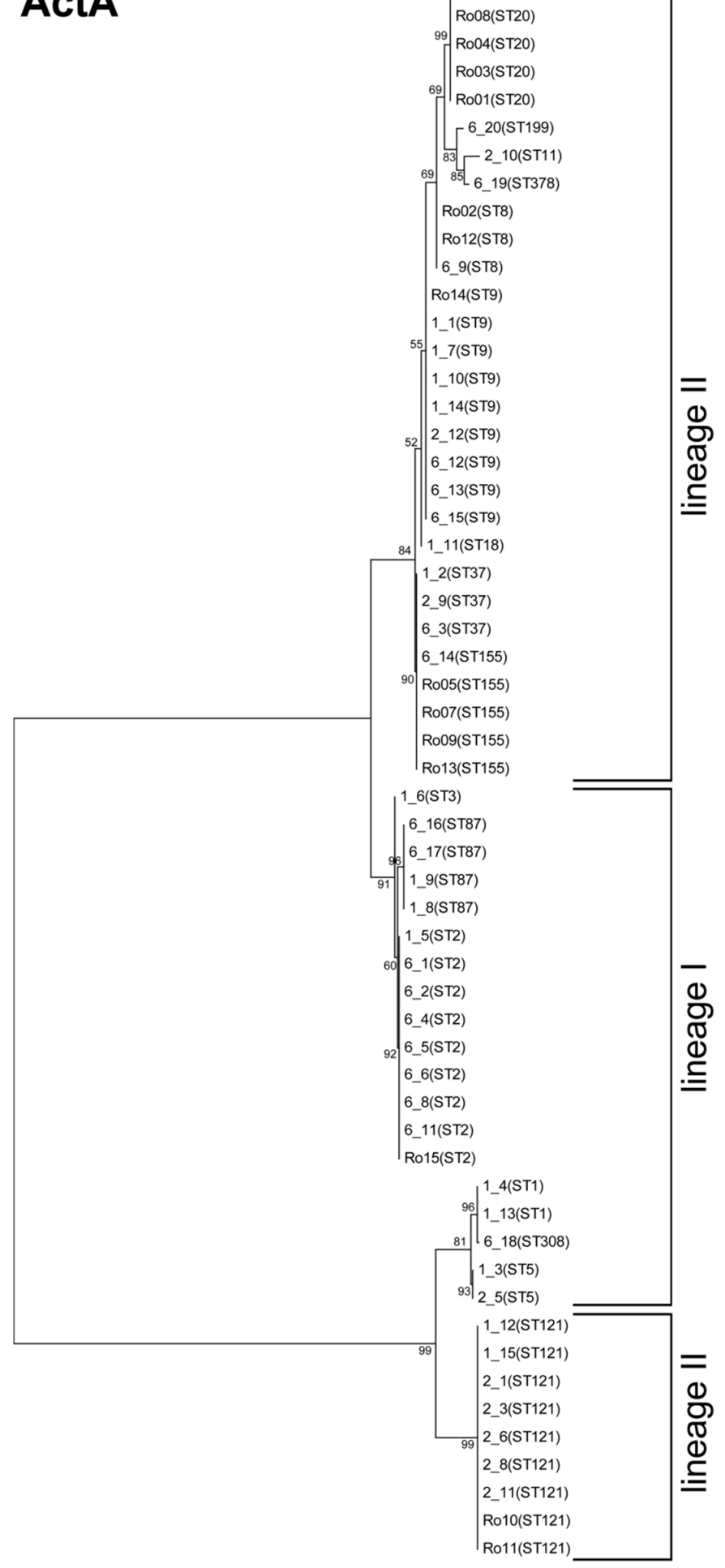

0.10

Figure 7. Phylogenetic analysis of ActA. Molecular phylogenetic analysis, based on the maximum likelihood method using ActA sequence, was calculated with MEGA7 using the JTT matrix-based model [22,26]. The tree is drawn to scale, with branch lengths measured by the number of substitutions per site. Bootstrap values $(100 \times$ resampling) are indicated at the respective nodes. The analysis involved 57 amino acid sequences. All positions with less than $75 \%$ site coverage were eliminated resulting in 633 positions in the final dataset. 


\section{Conclusions}

In this study, we characterized 57 L. monocytogenes isolates, which derived from 1474 illegally imported food products into the EU. The presence of L. monocytogenes in these types of samples uncovers new routes of pathogen transmission, which can endanger human health.

Although the L. monocytogenes strains originated from 17 different countries from four continents, we revealed moderate genotype diversity based on MLST and PFGE typing (16 STs belonging to 15 CCs and 34 unique pulsotypes). The most prevalent STs (ST121, ST9, ST2) of these international isolates are known to be among the most abundant STs, at least in Europe, underlining the global spread of certain STs. Two STs (ST20 and ST155), reported to be only rarely present, were highly abundant among food from the Romanian black market, showing a high regional prevalence of these STs.

The further characterization of virulence markers (InlA, LLO, and ActA) was important for an initial risk categorization. The highest diversity in virulence markers was, overall, observed within InlA (20 different InlA variants), and 14 strains (ST9 and ST121) harbored PMSC, indicating an attenuated virulence potential. An internally truncated ActA $(n=4)$ was identified among both genetic lineage I (ST1, ST5, and ST308) and II (ST121) strains. Interestingly, ST37 and ST155 carried the same ActA variant. LLO clearly separated genetic lineage I and II strains, but resulted in the lowest diversity (8 genetic variants).

Further studies, including a higher number of international L. monocytogenes isolates and using whole genome sequencing, will be necessary to study the population diversity of L. monocytogenes world-wide.

Supplementary Materials: The following are available online at http:/ /www.mdpi.com/2073-4425/9/9/428/s1. Table S1: Strain characteristics, Table S2: Primers used in this study.

Author Contributions: K.R., M.W. and D.S. conceived and designed the experiments; K.S.-B. and A.S. performed the experiments; K.S.-B., K.R. and B.S. analysed the data; K.R., B.S. and D.S. wrote the paper.

Funding: This research was funded by the EU 7th Framework Programme grant number 265877.

Acknowledgments: This study was supported by the 7th Framework Programme projects PROMISE (project number 265877). We thank David Rodríguez-Lázaro; Anca Ioana Nicolau; Bernd Appel for providing isolate and their support. The authors wish to thank Cameron McCulloch for assistance with the manuscript.

Conflicts of Interest: The authors declare no conflict of interests. The founding sponsors had no role in the design of the study; in the collection, analyses, or interpretation of data; in the writing of the manuscript, and in the decision to publish the results.

\section{References}

1. Mangili, A.; Gendreau, M.A. Transmission of infectious diseases during commercial air travel. Lancet 2005, 365, 989-996. [CrossRef]

2. Noordhuizen, J.; Surborg, H.; Smulders, F.J. On the efficacy of current biosecurity measures at EU borders to prevent the transfer of zoonotic and livestock diseases by travellers. Vet. Q. 2013, 33, 161-171. [CrossRef] [PubMed]

3. Kapperud, G.; Lassen, J.; Hasseltvedt, V. Salmonella infections in Norway: Descriptive epidemiology and a case-control study. Epidemiol. Infect. 1998, 121, 569-577. [CrossRef] [PubMed]

4. Nockler, K.; Wichmann-Schauer, H.; Hiller, P.; Muller, A.; Bogner, K. Trichinellosis outbreak in Bavaria caused by cured sausage from Romania, January 2007. Euro Surveill. 2007, 12, E070823. [CrossRef] [PubMed]

5. Beutlich, J.; Hammerl, J.A.; Appel, B.; Nockler, K.; Helmuth, R.; Jost, K.; Ludwig, M.L.; Hanke, C.; Bechtold, D.; Mayer-Scholl, A. Characterization of illegal food items and identification of foodborne pathogens brought into the European Union via two major German airports. Int. J. Food Microbiol. 2015, 209, 13-19. [CrossRef] [PubMed]

6. Allerberger, F.; Wagner, M. Listeriosis: A resurgent foodborne infection. Clin. Microbiol. Infect. 2010, 16, 16-23. [CrossRef] [PubMed]

7. Cossart, P.; Toledo-Arana, A. Listeria monocytogenes, a unique model in infection biology: An overview. Microbes Infect. 2008, 10, 1041-1050. [CrossRef] [PubMed] 
8. Vazquez-Boland, J.A.; Kuhn, M.; Berche, P.; Chakraborty, T.; Dominguez-Bernal, G.; Goebel, W.; Gonzalez-Zorn, B.; Wehland, J.; Kreft, J. Listeria pathogenesis and molecular virulence determinants. Clin. Microbiol. Rev. 2001, 14, 584-640. [CrossRef] [PubMed]

9. European Food Safety Authority; European Centre for Disease Prevention and Control. The European Union summary report on trends and sources of zoonoses, zoonotic agents and food-borne outbreaks in 2015. EFSA J. 2016, 14, e04634. [CrossRef]

10. Gandhi, M.; Chikindas, M.L. Listeria: A foodborne pathogen that knows how to survive. Int. J. Food Microbiol. 2007, 113, 1-15. [CrossRef] [PubMed]

11. Chaturongakul, S.; Raengpradub, S.; Wiedmann, M.; Boor, K.J. Modulation of stress and virulence in Listeria monocytogenes. Trends Microbiol. 2008, 16, 388-396. [CrossRef] [PubMed]

12. Schoder, D.; Strauss, A.; Szakmary-Brandle, K.; Stessl, B.; Schlager, S.; Wagner, M. Prevalence of major foodborne pathogens in food confiscated from air passenger luggage. Int. J. Food Microbiol. 2015, 209, 3-12. [CrossRef] [PubMed]

13. Rodriguez-Lazaro, D.; Ariza-Miguel, J.; Diez-Valcarce, M.; Stessl, B.; Beutlich, J.; Fernandez-Natal, I.; Hernandez, M.; Wagner, M.; Rovira, J. Identification and molecular characterization of pathogenic bacteria in foods confiscated from non-EU flights passengers at one Spanish airport. Int. J. Food Microbiol. 2015, 209, 20-25. [CrossRef] [PubMed]

14. Ciolacu, L.; Stessl, B.; Bolocan, A.S.; Oniciuc, E.A.; Wagner, M.; Rychli, K.; Nicolau, A.I. Tracking foodborne pathogenic bacteria in raw and ready-to-eat food illegally sold at the eastern EU border. Foodborne Pathog. Dis. 2016, 13, 148-155. [CrossRef] [PubMed]

15. Bonazzi, M.; Lecuit, M.; Cossart, P. Listeria monocytogenes internalin and E-cadherin: From structure to pathogenesis. Cell. Microbiol. 2009, 11, 693-702. [CrossRef] [PubMed]

16. Schnupf, P.; Portnoy, D.A. Listeriolysin O: A phagosome-specific lysin. Microbes Infect. 2007, 9, $1176-1187$. [CrossRef] [PubMed]

17. Camejo, A.; Carvalho, F.; Reis, O.; Leitao, E.; Sousa, S.; Cabanes, D. The arsenal of virulence factors deployed by Listeria monocytogenes to promote its cell infection cycle. Virulence 2011, 2, 379-394. [CrossRef] [PubMed]

18. Travier, L.; Guadagnini, S.; Gouin, E.; Dufour, A.; Chenal-Francisque, V.; Cossart, P.; Olivo-Marin, J.C.; Ghigo, J.M.; Disson, O.; Lecuit, M. ActA promotes Listeria monocytogenes aggregation, intestinal colonization and carriage. PLoS Pathog. 2013, 9, e1003131. [CrossRef] [PubMed]

19. Ciolacu, L.; Nicolau, A.I.; Wagner, M.; Rychli, K. Listeria monocytogenes isolated from food samples from a Romanian black market show distinct virulence profiles. Int. J. Food Microbiol. 2015, 209, 44-51. [CrossRef] [PubMed]

20. Ragon, M.; Wirth, T.; Hollandt, F.; Lavenir, R.; Lecuit, M.; Le Monnier, A.; Brisse, S. A new perspective on Listeria monocytogenes evolution. PLoS Pathog. 2008, 4, e1000146. [CrossRef] [PubMed]

21. Cantinelli, T.; Chenal-Francisque, V.; Diancourt, L.; Frezal, L.; Leclercq, A.; Wirth, T.; Lecuit, M.; Brisse, S. "Epidemic clones" of Listeria monocytogenes are widespread and ancient clonal groups. J. Clin. Microbiol. 2013, 51, 3770-3779. [CrossRef] [PubMed]

22. Kumar, S.; Stecher, G.; Tamura, K. MEGA7: Molecular evolutionary genetics analysis version 7.0 for bigger datasets. Mol. Biol. Evol. 2016, 33, 1870-1874. [CrossRef] [PubMed]

23. Pulsenet International. 2013. Available online: http://www.pulsenetinternational.org/assets/PulseNet/ uploads/pfge/PNL04_ListeriaPFGEProtocol.pdf (accessed on 15 July 2018).

24. Tenover, F.C.; Arbeit, R.D.; Goering, R.V.; Mickelsen, P.A.; Murray, B.E.; Persing, D.H.; Swaminathan, B. Interpreting chromosomal DNA restriction patterns produced by pulsed-field gel electrophoresis: Criteria for bacterial strain typing. J. Clin. Microbiol. 1995, 33, 2233-2239. [PubMed]

25. Katoh, K.; Toh, H. Recent developments in the MAFFT multiple sequence alignment program. Brief. Bioinform. 2008, 9, 286-298. [CrossRef] [PubMed]

26. Jones, D.T.; Taylor, W.R.; Thornton, J.M. The rapid generation of mutation data matrices from protein sequences. Comput. Appl. Biosci. 1992, 8, 275-282. [CrossRef] [PubMed]

27. Nielsen, E.M.; Björkman, J.T.; Kiil, K.; Grant, K.; Dallman, T.; Painset, A.; Amar, C.; Roussel, S.; Guillier, L.; Félix, B.; et al. Closing gaps for performing a risk assessment on Listeria monocytogenes in ready-to-eat (RTE) foods: Activity 3, the comparison of isolates from different compartments along the food chain, and from humans using whole genome sequencing (WGS) analysis. EFSA Support. Publ. 2017, 14, 1151E. [CrossRef] 
28. Chenal-Francisque, V.; Lopez, J.; Cantinelli, T.; Caro, V.; Tran, C.; Leclercq, A.; Lecuit, M.; Brisse, S. Worldwide distribution of major clones of Listeria monocytogenes. Emerg. Infect. Dis. 2011, 17, 1110-1112. [CrossRef] [PubMed]

29. Maury, M.M.; Tsai, Y.-H.; Charlier, C.; Touchon, M.; Chenal-Francisque, V.; Leclercq, A.; Criscuolo, A.; Gaultier, C.; Roussel, S.; Brisabois, A.; et al. Uncovering Listeria monocytogenes hypervirulence by harnessing its biodiversity. Nat. Genet. 2016, 48, 308-313. [CrossRef] [PubMed]

30. Moura, A.; Criscuolo, A.; Pouseele, H.; Maury, M.M.; Leclercq, A.; Tarr, C.; Bjorkman, J.T.; Dallman, T.; Reimer, A.; Enouf, V.; et al. Whole genome-based population biology and epidemiological surveillance of Listeria monocytogenes. Nat. Microbiol. 2016, 2, 16185. [CrossRef] [PubMed]

31. Jensen, A.K.; Björkman, J.T.; Ethelberg, S.; Kiil, K.; Kemp, M.; Nielsen, E.M. Molecular typing and epidemiology of human listeriosis cases, Denmark, 2002-2012. Emerg. Infect. Dis. 2016, 22, 625-633. [CrossRef] [PubMed]

32. Linke, K.; Ruckerl, I.; Brugger, K.; Karpiskova, R.; Walland, J.; Muri-Klinger, S.; Tichy, A.; Wagner, M.; Stessl, B. Reservoirs of Listeria species in three environmental ecosystems. Appl. Environ. Microbiol. 2014, 80, 5583-5592. [CrossRef] [PubMed]

33. Amajoud, N.; Leclercq, A.; Soriano, J.M.; Bracq-Dieye, H.; El Maadoudi, M.; Senhaji, N.S.; Kounnoun, A.; Moura, A.; Lecuit, M.; Abrini, J. Prevalence of Listeria spp. and characterization of Listeria monocytogenes isolated from food products in Tetouan, Morocco. Food Control 2018, 84, 436-441. [CrossRef]

34. Martin, B.; Perich, A.; Gomez, D.; Yanguela, J.; Rodriguez, A.; Garriga, M.; Aymerich, T. Diversity and distribution of Listeria monocytogenes in meat processing plants. Food Microbiol. 2014, 44, 119-127. [CrossRef] [PubMed]

35. Fagerlund, A.; Langsrud, S.; Schirmer, B.C.; Moretro, T.; Heir, E. Genome analysis of Listeria monocytogenes sequence type 8 strains persisting in salmon and poultry processing environments and comparison with related strains. PLoS ONE 2016, 11, e0151117. [CrossRef] [PubMed]

36. Muhterem-Uyar, M.; Ciolacu, L.; Wagner, K.H.; Wagner, M.; Schmitz-Esser, S.; Stessl, B. New aspects on Listeria monocytogenes ST5-ECVI predominance in a heavily contaminated cheese processing environment. Front. Microbiol. 2018, 9, 64. [CrossRef] [PubMed]

37. Wang, Y.; Jiao, Y.; Lan, R.; Xu, X.; Liu, G.; Wang, X.; Zhang, L.; Pang, H.; Jin, D.; Dai, H.; et al. Characterization of Listeria monocytogenes isolated from human listeriosis cases in China. Emerg. Microbes Infect. 2015, 4, e50. [CrossRef] [PubMed]

38. Halbedel, S.; Prager, R.; Fuchs, S.; Trost, E.; Werner, G.; Flieger, A. Whole genome sequencing of recent Listeria monocytogenes isolates from Germany reveals population structure and disease clusters. J. Clin. Microbiol. 2018. [CrossRef] [PubMed]

39. Chen, Y.; Ross, W.H.; Whiting, R.C.; Van Stelten, A.; Nightingale, K.K.; Wiedmann, M.; Scott, V.N. Variation in Listeria monocytogenes dose responses in relation to subtypes encoding a full-length or truncated internalin A. Appl. Environ. Microbiol. 2011, 77, 1171-1180. [CrossRef] [PubMed]

40. Nightingale, K.K.; Ivy, R.A.; Ho, A.J.; Fortes, E.D.; Njaa, B.L.; Peters, R.M.; Wiedmann, M. inlA premature stop codons are common among Listeria monocytogenes isolates from foods and yield virulence-attenuated strains that confer protection against fully virulent strains. Appl. Environ. Microbiol. 2008, 74, 6570-6583. [CrossRef] [PubMed]

41. Nightingale, K.K.; Windham, K.; Martin, K.E.; Yeung, M.; Wiedmann, M. Select Listeria monocytogenes subtypes commonly found in foods carry distinct nonsense mutations in inlA, leading to expression of truncated and secreted internalin $\mathrm{A}$, and are associated with a reduced invasion phenotype for human intestinal epithelial cells. Appl. Environ. Microbiol. 2005, 71, 8764-8772. [CrossRef] [PubMed]

42. Olier, M.; Pierre, F.; Rousseaux, S.; Lemaitre, J.P.; Rousset, A.; Piveteau, P.; Guzzo, J. Expression of truncated Internalin A is involved in impaired internalization of some Listeria monocytogenes isolates carried asymptomatically by humans. Infect. Immun. 2003, 71, 1217-1224. [CrossRef] [PubMed]

43. Rychli, K.; Wagner, E.M.; Ciolacu, L.; Zaiser, A.; Tasara, T.; Wagner, M.; Schmitz-Esser, S. Comparative genomics of human and non-human Listeria monocytogenes sequence type 121 strains. PLoS ONE 2017, 12, e0176857. [CrossRef] [PubMed]

44. Schmitz-Esser, S.; Müller, A.; Stessl, B.; Wagner, M. Genomes of sequence type 121 Listeria monocytogenes strains harbor highly conserved plasmids and prophages. Front. Microbiol. 2015, 6, 380. [CrossRef] [PubMed] 
45. Ebner, R.; Stephan, R.; Althaus, D.; Brisse, S.; Maury, M.; Tasara, T. Phenotypic and genotypic characteristics of Listeria monocytogenes strains isolated during 2011-2014 from different food matrices in Switzerland. Food Control 2015, 57, 321-326. [CrossRef]

46. Gelbicova, T.; Kolackova, I.; Pantucek, R.; Karpiskova, R. A novel mutation leading to a premature stop codon in inlA of Listeria monocytogenes isolated from neonatal listeriosis. New Microbiol. 2015, 38, $293-296$. [PubMed]

47. Rousseaux, S.; Olier, M.; Lemaitre, J.P.; Piveteau, P.; Guzzo, J. Use of PCR-restriction fragment length polymorphism of inlA for rapid screening of Listeria monocytogenes strains deficient in the ability to invade Caco-2 cells. Appl. Environ. Microbiol. 2004, 70, 2180-2185. [CrossRef] [PubMed]

48. Lecuit, M.; Ohayon, H.; Braun, L.; Mengaud, J.; Cossart, P. Internalin of Listeria monocytogenes with an intact leucine-rich repeat region is sufficient to promote internalization. Infect. Immun. 1997, 65, 5309-5319. [PubMed]

49. Bierne, H.; Sabet, C.; Personnic, N.; Cossart, P. Internalins: A complex family of leucine-rich repeat-containing proteins in Listeria monocytogenes. Microbes Infect. 2007, 9, 1156-1166. [CrossRef] [PubMed]

50. Gray, M.J.; Zadoks, R.N.; Fortes, E.D.; Dogan, B.; Cai, S.; Chen, Y.; Scott, V.N.; Gombas, D.E.; Boor, K.J.; Wiedmann, M. Listeria monocytogenes isolates from foods and humans form distinct but overlapping populations. Appl. Environ. Microbiol. 2004, 70, 5833-5841. [CrossRef] [PubMed]

51. Lety, M.A.; Frehel, C.; Berche, P.; Charbit, A. Critical role of the N-terminal residues of listeriolysin O in phagosomal escape and virulence of Listeria monocytogenes. Mol. Microbiol. 2002, 46, 367-379. [CrossRef] [PubMed]

52. Lety, M.-A.; Frehel, C.; Dubail, I.; Beretti, J.-L.; Kayal, S.; Berche, P.; Charbit, A. Identification of a PEST-like motif in listeriolysin $\mathrm{O}$ required for phagosomal escape and for virulence in Listeria monocytogenes. Mol. Microbiol. 2001, 39, 1124-1139. [CrossRef] [PubMed]

53. Schnupf, P.; Hofmann, J.; Norseen, J.; Glomski, I.J.; Schwartzstein, H.; Decatur, A.L. Regulated translation of listeriolysin O controls virulence of Listeria monocytogenes. Mol. Microbiol. 2006, 61, 999-1012. [CrossRef] [PubMed]

54. Glomski, I.J.; Gedde, M.M.; Tsang, A.W.; Swanson, J.A.; Portnoy, D.A. The Listeria monocytogenes hemolysin has an acidic $\mathrm{pH}$ optimum to compartmentalize activity and prevent damage to infected host cells. J. Cell Biol. 2002, 156, 1029-1038. [CrossRef] [PubMed]

55. Michel, E.; Reich, K.A.; Favier, R.; Berche, P.; Cossart, P. Attenuated mutants of the intracellular bacterium Listeria monocytogenes obtained by single amino-acid substitutions in Listeriolysin-O. Mol. Microbiol. 1990, 4, 2167-2178. [CrossRef] [PubMed]

56. Tang, P.; Rosenshine, I.; Cossart, P.; Finlay, B.B. Listeriolysin O activates mitogen-activated protein kinase in eucaryotic cells. Infect. Immun. 1996, 64, 2359-2361. [PubMed]

57. Melton-Witt, J.A.; McKay, S.L.; Portnoy, D.A. Development of a single-gene, signature-tag-based approach in combination with alanine mutagenesis to identify listeriolysin $\mathrm{O}$ residues critical for the in vivo survival of Listeria monocytogenes. Infect. Immun. 2012, 80, 2221-2230. [CrossRef] [PubMed]

58. Skoble, J.; Portnoy, D.A.; Welch, M.D. Three regions within ActA promote Arp2/3 complex-mediated actin nucleation and Listeria monocytogenes motility. J. Cell Biol. 2000, 150, 527-538. [CrossRef] [PubMed]

59. Smith, G.A.; Theriot, J.A.; Portnoy, D.A. The tandem repeat domain in the Listeria monocytogenes ActA protein controls the rate of actin-based motility, the percentage of moving bacteria, and the localization of vasodilator-stimulated phosphoprotein and profilin. J. Cell Biol. 1996, 135, 647-660. [CrossRef] [PubMed]

60. Lasa, I.; David, V.; Gouin, E.; Marchand, J.B.; Cossart, P. The amino-terminal part of ActA is critical for the actin-based motility of Listeria monocytogenes; the central proline-rich region acts as a stimulator. Mol. Microbiol. 1995, 18, 425-436. [CrossRef] [PubMed] 
61. Pistor, S.; Chakraborty, T.; Walter, U.; Wehland, J. The bacterial actin nucleator protein ActA of Listeria monocytogenes contains multiple binding sites for host microfilament proteins. Curr. Biol. 1995, 5, 517-525. [CrossRef]

62. Roberts, A.J.; Wiedmann, M. Allelic exchange and site-directed mutagenesis probe the contribution of ActA amino-acid variability to phosphorylation and virulence-associated phenotypes among Listeria monocytogenes strains. FEMS Microbiol. Lett. 2006, 254, 300-307. [CrossRef] [PubMed] 